\begin{tabular}{|l|l|l||}
\hline \multicolumn{2}{|c|}{ PublisherInfo } \\
\hline \hline PublisherName & $:$ & BioMed Central \\
\hline \hline PublisherLocation & $:$ & London \\
\hline \hline PublisherImprintName & $:$ & BioMed Central \\
\hline \hline
\end{tabular}

\title{
Predicting outcome after pulmonary resection
}

\begin{tabular}{|l|l|l||}
\hline \multicolumn{2}{|c|}{ ArticleInfo } \\
\hline \hline ArticleID & $:$ & 4125 \\
\hline \hline ArticleDOI & $:$ & $10.1186 /$ ccf-1999-602 \\
\hline \hline ArticleCitationID & $:$ & 602 \\
\hline \hline ArticleSequenceNumber & $:$ & 62 \\
\hline \hline ArticleCategory & $:$ & Paper Report \\
\hline \hline ArticleFirstPage & $:$ & 1 \\
\hline \hline ArticleLastPage & $:$ & 4 \\
\hline \hline & & RegistrationDate : 1999-6-15 \\
\hline ArticleHistory & $:$ & OnlineDate \\
\hline \hline ArticleCopyright & $:$ & Current Science Ltd1999-6-15 \\
\hline \hline ArticleGrants & $:$ & \\
\hline \hline ArticleContext & $:$ & 130541111 \\
\hline \hline
\end{tabular}




\section{Keywords}

Lung resection, outcome

\section{Comments}

Outcome data of this nature are of interest to those providing intensive care facilities for patients following pulmonary resections. Of specfic note, a high proportion of these patients $(7.9 \%$ of lobectomies and $10.6 \%$ of pneumonectomies) required reintubation presumably for respiratory failure. It is also of interest that failure to wean within $48 \mathrm{~h}$ was another variable recorded as morbidity, suggesting these patients are treated differently in the immediate operative course in the United States. The predictors of morbidity and mortality that the authors identified are intuitively not surprising and reflect poor general status (low albumin, do not resuscitate status, old age) and operative difficulty (blood transfusion). However, the prospective and blinded collection of a range of data make the results of interest. The drawbacks of these data are the fact that specific complications such as bronchopleural fistula are not recorded and the patient base is $98.7 \%$ male.

\section{Introduction}

The National Veterans Affairs Surgical Quality Improvement Program was designed as a method of collecting data on surgical operations with a view to assessing outcome and quality of care at different institutions. This project looked at a sample of 3516 patients from their database who had undergone major pulmonary resections.

\section{Aims}

To produce a risk-adjusted model of mortality and morbidity for patients undergoing major pulmonary resections.

\section{Methods}


A total of 3516 patients undergoing major pulmonary resection were assessed, of which 2949 underwent lobectomy and 567 underwent pneumonectomy. An independent nurse reviewer recorded 122 separate variables for each operation, including four demographic, 43 historical and 17 preoperative variables, and 13 intra-operative and operation-specific variables. In the 30-day postoperative period, mortality and morbidity statistics and the presence of any one of 21 pre-defined postoperative complications were recorded. Statistical models were developed to compare the type of operation performed and the pre- and intra-operative values.

\section{Results}

Within 30 days of the operation, there was a $4.0 \%$ and $11.5 \%$ mortality rate for lobectomy and pneumonectomy, respectively. Postoperative morbidity was $23.8 \%$ and $25.7 \%$ for lobectomy and pneumonectomy, respectively. With univariate analysis, there were 24 preoperative and nine laboratory variables associated with an increased risk of 30-day mortality and morbidity, and four and three intraoperative variables, respectively. Of these, 18 preoperative and six laboratory variables were commonly significant for both mortality and morbidity.

Multivariate analysis resulted in nine significant, independent, preoperative predictors for 30-day mortality, including age, serum albumin and disseminated cancer. Predictors for 30-day morbidity included age, serum albumin and weight loss of more than $10 \%$.

c-Indexes for the mortality and morbidity models indicated a moderate level of predictability.

\section{Discussion}

This is the largest study of its kind to date, providing a method of predicting the probability of an adverse reaction in a particular patient within 30 days of major surgery. Rates of mortality and morbidity in this study are comparable with those published elsewhere. The subjects in this study were predominantly male, with no subspeciality procedure-specific morbidity data collected. There were different variables predicting mortality and morbidity, social factors such as smoking and weight being relevant in the morbidity model. The authors demonstrate the feasibility of a multicenter perioperative study and comment on the possibility of including other variables to increase the value of the predictability models. 


\section{References}

1. Harpole D, DeCamp M Jr, Daley J, Hur K, Oprian C, Hederson W, Khuri S: Prognostic models of thirty-day mortality and morbidity after major pulmonary resection. J Thorac Cardiovasc Surg. 1999, 117: 969-979. 